Business and Economics Research Journal

Volume 8 Number 32017

pp. 379-394

ISSN: $1309-2448$

DOI Number: 10.20409/berj.2017.56

\title{
Exchange Rates and Monetary Fundamentals: Evidence from Turkey ${ }^{1}$
}

\author{
Oğuz Tümtürk
}

\begin{abstract}
The main purpose of the study is to investigate the predictability of exchange rates by using the long horizon regression approach (or the Error Correction Model) derived from the Vector Error Correction Model for Turkey. The data cover the period over the period of 2001:Q1-2016:Q2 as Turkey has adopted floating exchange rate regime since 2001 crisis. The predictive ability of the long horizon regression was evaluated according to in-sample fit and outof sample analyses. The in-sample fit results indicate that the fundamentals are useful to explain the long horizon changes in exchange rates under the assumption of country specific money demand elasticities. On the other hand, the out-of sample analysis results present evidence that the Error Correction Model outperforms the Random Walk Model during the forecast period, 2008:Q1-2013:Q2; however, the Random Walk beats the Error Correction Model around 2008 recession period owing to elevated information uncertainty and short termism.
\end{abstract}

Keywords: Exchange Rates, Monetary Fundamentals, Random Walk, Forecast Errors

JEL Classification: F31, F37, F41

\section{Introduction}

Exchange rates, which is simply the price of one currency in terms of another currency, are one of the key component of the macroeconomics discussions in the literature. If one want to understand why some currencies depreciate and others appreciate, the factors that cause the change in supply and demand of currencies must be investigated. These factors include various fundamentals such as real income, inflation rates, real interest rates, consumer preferences, and government trade policy. For example, Purchasing Power Parity (PPP) states that a country's currency will depreciate by an amount equal to the excess of domestic inflation over foreign inflation while Uncovered Interest Parity (UIP) suggests that the interest rate differentials change the exchange rates. Traditional Flow Approach, which is also called the balance-ofpayments view, states that exchange rate moves to keep the balance of payments in equilibrium under the assumption of no government interventions. On the other hand, nominal exchange rate fluctuations should reflect movements in a country's monetary fundamentals such as relative money, output, interest rates and prices, according to the Monetary Model of Exchange Rate Determination.

One of the important debates centers on the international economics is the difficulty of predicting exchange rates by using monetary fundamentals such as money supplies, outputs, and interest rates. As stated above, some theories in the economic literature claim that the exchange rates might be determined by such fundamental variables. However, since Meese and Rogoff (1983), it has been considered that exchange rates are very difficult to predict using monetary fundamentals; in particular, a simple random walk

aRes. Asst., PhD., Ordu University Unye Faculty of Economics and Administrative Sciences, Ordu, Turkiye, oguz.tumturk@gmail.com 
without drift (RW), is found to produce better exchange rate forecasts than fundamental-based exchange rate models. In other words, fundamental variables do not help predict future changes in exchange rates

Meese and Rogoff's (1983) finding was a shock for economists since monetary fundamentals have long been considered key determinants of exchange rates. If their finding is true, then all exchange rate models based on the fundamentals are misleading. Therefore, large numbers of studies have attempted to refute Meese and Rogoff's findings and find positive results in favor of fundamentals-based models. One of the most well-known rebuttals to Meese and Rogoff's work is Mark's (1995) study. Mark concludes in his study that monetary fundamentals contain predictive power for exchange rate. He used the long horizon regression (or Error Correction Model (ECM)) derived from the VECM (Vector Error Correction Model). However, these two studies are not the only ones testing the predictive ability of exchange rate models. Several models such as the single equation linear models, single-equation ECM, multi-equation VECM models, time-varying parameter models, and panel models have been used in the literature in the attempt to predict exchange rates. Even though most of the authors are unable to document short-run exchange rate predictability, some of them find evidence of long horizon predictability. Nevertheless, the literature has remained pessimistic about the link between exchange rates and fundamentals.

The main purpose of the study is to investigate the exchange rate predictability in Turkey by using the monetary fundamentals in the ECM. This study first examines the in-sample fit of the ECM model, and then evaluates the out-of sample forecast performance of the ECM against benchmark RW model. The fundamental value of exchange rate used in this study is obtained from Frankel-Bilson Monetary Model. The error correction term is constructed under the assumptions of zero/nonzero interest rate differentials and country specific money demand elasticities to satisfy the cointegration assumption between fundamentals and exchange rates. The in-sample analysis results present evidence that monetary fundamentals are useful to explain the long horizon changes in the logarithm of the exchange rates while the out-of sample analysis results suggest that whether the ECM or the RW explains the nature of exchange rate changes might be considered that time varying.

This study covers the period from 2001:Q1 to 2016:Q2 as Turkey has adopted floating exchange rate regime since 2001 crisis, which was the biggest financial crisis in the history of the Republic of Turkey. The main reasons of the crisis were large stock of foreign debts, increasing current account deficits, and rising interest rates triggered by political instability and massive capital outflows. Before the crisis, Central Bank of the Republic of Turkey (CBRT) allowed the exchange rates to fluctuate within the band (crawling bands). However, the 2001 crisis in Turkey forced the monetary authorities to abandon the crawling bands, and CBRT has started to experience floating exchange rates. Since 2001, CBRT intervenes in the exchange rate market to dampen excessive volatility of exchange rates and build reserves, but exchange rates are not driven by $C B R T$, suggesting that $C B R T$ does not aim to determine the direction and current level of the exchange rates.

The organization of the article proceeds as follows. The following section provides a brief overview of the literature published on related studies. Section 3 discusses the data definitions while Section 4 introduces the theoretical framework of the long horizon regression, monetary fundamentals, and methodology. Sections 5 and 6 contain the empirical results of the in-sample and out-of sample analyses, respectively while concluding remarks are contained in Section 7.

\section{Literature Review}

There are many studies testing the predictive power of the fundamentals-based exchange rate models based on the monetary fundamentals in the exchange rate literature. The objective of this section is to review the related literature on predicting exchange rates.

The monetary model of exchange rate determination emerged as one of the main exchange rate models in literature. However, using exchange rate data (relative to the United States dollar) for the United Kingdom, Japan and Germany, Meese and Rogoff (1983) presented evidence that monetary models' forecasts cannot outperform the simple RW forecasts by using single-equation models. Contrary to Meese and Rogoff, using single-equation ECM and exchange rate data (relative to the United States dollar) for Canada, Germany, 
Japan and Switzerland over the period of 1973 and 1991, Mark (1995) provided support in favor of a fundamental model in the long horizon. Nevertheless, Mark's paper has been criticized by the scholars since he assumed that exchange rates and fundamentals are cointegrated. For example, Berkowitz and Giorgianni (2001) claimed that if the cointegration assumption does not hold, then the tests results are biased toward rejecting the null hypothesis of no predictability. Chinn and Meese (1995) used the same model used by Mark, and confirmed that fundamental exchange rate models forecasted no better than a RW model for short-term predictions. For longer periods, these models significantly outperformed the RW model. On the other hand, Kilian (1999) and Groen (1999) were unable to document predictive ability of the monetary model used by Mark in the long run.

Engel (1994) showed that a Markov Switching performs well in-sample for 18 industrialized countries exchange rates at quarterly frequencies. By the mean squared error criterion, the Markov Model did not produce superior forecasts to the RW. Frommel, Macdonald and Menkhoff (2005) used the real interest rate differential (RID) model which is an extended version of the Frankel-Bilson model by introducing Markov regime switches for three industrialized countries currencies (Germany, United Kingdom, Japan) relative to the United States dollar. They found the evidence of the relationship between exchange rates and the fundamentals. Also, Mahavan and Wagner (1999), Marsh (2000), and Taylor and Peel (2000) studied to analyze the monetary model, and they provided support in favor of a fundamental model. In literature, traditional Multi-Equation Vector Error Correction Model (VECM) is also used. Based on the empirical evidences on VECMs, MacDonald and Taylor (1993) found supportive evidence while Rapach and Wohar (2002), and Diebold, Gardeazabal and Yilmaz (1994) documented more negative results.

Several panel models have also been considered in the literature. Panel models generally produced better forecast than the RW model. Mark and Sul (2001) examined the long run relationship between nominal exchange rates and monetary fundamentals in a panel of 19 industrialized countries. Panel cointegration test suggested that exchange rate is cointegrated with fundamentals, and these fundamentals significantly predicted future exchange rate movements. They also showed the dominance of fundamentals over the RW out-of sample forecasts. Cerra and Saxena (2010) tested for cointegration and out-of sample analysis of monetary models for the nominal exchange rate for a panel of 98 countries. For the in-sample analysis, they found a cointegration relation between the nominal exchange rates and monetary fundamentals. For the out-of sample analysis, they concluded that the fundamental-based models beat the RW model. Also, some other leading empirical studies including Groen (2005) and Engel, Mark and West (2007) provided a support in favor of the panel ECMs.

Almost all studies above demonstrate the relationship between exchange rates and fundamentals for the industrialized countries. The exchange rate predictability has been also subjected to theoretical and empirical research in the emerging countries including Turkey. Uz and Ketenci (2008) employed the panel cointegration tests for the newly entered ten EU members and Turkey, and they indicated a long-run relationship between nominal exchange rate and monetary variables. In addition, their empirical evidences revealed that out-of sample predictability of error-correction outperformed the RW model after two years. Galimberti and Moura (2013) investigated the exchange rate predictability of fifteen emerging economies including Turkey. By evaluating various specifications for the Taylor rule exchange rate model and their outof sample performances, Galimberti and Moura concluded that a present-value forward-looking specification showed strong evidence of exchange rate predictability. Korap (2008) investigated the exchange rate determination mechanism for the Turkish economy. He concluded that TL/US\$ nominal exchange rate is cointegrated with the monetary fundamentals. The results also revealed that fundamental based monetary model outperforms the benchmark RW model. Dabrowski, Papiez and Smiech (2014) examined the monetary model and exchange rate movements in Central and Eastern European countries (the Czech Republic, Hungary, Moldova, Poland, Romania, Serbia, Turkey, and Ukraine). Using quarterly panel data, 2001:Q42012:Q4, they presented evidence of cointegration between exchange rates and macroeconomic fundamentals. They also concluded that exchange rates returned to the long-run relation implied by the monetary model based on the Granger causality analysis. 


\section{Data}

The data are quarterly observations for Turkey and the United States. The United States is the numeraire country. The data consist of $T=62$ observations extending from 2001:Q1 to 2016:Q2. The exchange rate data are the United States dollar price of the Turkish Lira and were obtained from the CBRT. M1 data for Turkey and the United States were obtained from the CBRT and Federal Reserve Economic Data (FRED), respectively. Real income data for the United States and Turkey are measured by quarterly real GDP and were obtained from the Organization for Economic Co-operation and Development (OECD) and FRED, respectively. Similarly, interest rate data for Turkey and the United States are obtained from the FRED and OECD, respectively.

\section{Theoretical Framework and Methodology}

\subsection{Long Horizon Regression and the Monetary Fundamentals}

The model used in this study is long horizon regression which has been widely used since the work by Mark (1995).

$$
s_{t+k}-s_{t}=\alpha_{k}+\gamma_{k}\left(f_{t}-s_{t}\right)+v_{t+k, t} \quad t \quad k=1,2, \ldots \ldots, k
$$

where $\alpha_{k}$ and $\gamma_{k}$ are the linear least-squares projection coefficients and $v_{t+k, t}$ is the projection error. Error correction term $z_{t}=f_{t}-s_{t}$ shows the difference between the current fundamentals $f_{t}$ and the current exchange rate $s_{t}$, and determines the k-period-ahead change in the exchange rate. The fundamental value of the exchange rate $f_{t}$ is obtained from Frankel Bilson Monetary Model based on Monetary Model of Exchange Rate Determination. Following section provides brief introduction of the Monetary Model of Exchange Rate Determination.

\subsubsection{The Monetary Model of Exchange Rate Determination}

The Monetary Model of Exchange Rate Determination consists of a pair of stable money demand functions and purchasing-power parity.

\section{i) Money Market Equations:}

$$
\begin{aligned}
& \mathrm{m}_{\mathrm{t}}-\mathrm{p}_{\mathrm{t}}=\beta \mathrm{y}_{\mathrm{t}}-\lambda \mathrm{i}_{\mathrm{t}} \\
& \mathrm{m}_{\mathrm{t}}^{*}-\mathrm{p}_{\mathrm{t}}^{*}=\beta \mathrm{y}_{\mathrm{t}}^{*}-\lambda \mathrm{i}_{\mathrm{t}}^{*}
\end{aligned}
$$

$\beta$ is the income elasticity of money demand, and $\lambda$ is the interest rate semi-elasticity of money demand in home country. $m_{t}, p_{t}, y_{t}$ and $i_{t}$ denote the log-levels of the money supply, the price level, income, and the level of the interest rate, respectively, at time $t$. It is assumed that the coefficients are symmetric and asterisks denote foreign (numeraire) country variables.

\section{ii) Purchasing Power Parity (PPP):}

Price levels and the exchange rate are related through purchasing-power parity.

$$
s_{t}=p_{t}-p_{t}^{*}
$$

When solving money market equations (2) and (3) with respect to $p_{t}$ and $p_{t}{ }^{*}$ and plug into the equation (4), the flexible price version of the Monetary Model, which is also known Frenkel-Bilson Model, is obtained: 


$$
f_{t}=\left(m_{t}-m_{t}^{*}\right)-\beta\left(y_{t}-y_{t}^{*}\right)+\mu\left(i_{t}-i_{t}^{*}\right)
$$

Essentially, Mark (1995) used the Frenkel-Bilson Model in regression (1) assuming that $\beta=1$ for home and numerarire countries. Also, the interest rate differential between industrialized countries is assumed to be equal to zero, so that the fundamentals term is $f_{t}=\left(m_{t}-m_{t}^{*}\right)-\left(y_{t}-y_{t}^{*}\right)$.

\subsubsection{Relationship to the Vector Error-Correction Model}

The long horizon regression (1) is derived from the VECM with the help of Berkowitz and Giorgianni (2001). The long-horizon regression is based on the assumption that nominal exchange rates and fundamentals are cointegrated with cointegration vector $\left[\begin{array}{ll}1 & -1\end{array}\right]^{\top}$. Both $f_{t}=\left(m_{t}-m_{t}{ }^{*}\right)-\left(y_{t}-y_{t}{ }^{*}\right)$ and $s_{t}$ are assumed to be integrated of order one, I(1). Then, there exists a valid VECM representation based on the Granger Representation Theorem:

$$
\begin{aligned}
& \Delta s_{t+1}=\lambda_{1}\left(f_{t}-s_{t}\right)+\omega_{1, t+1} \\
& \Delta f_{t+1}=\lambda_{2}\left(f_{t}-s_{t}\right)+\omega_{2, t+1}
\end{aligned}
$$

The two terms represented by $\omega_{1, t+1}$ and $\omega_{2, t+1}$ are white noise disturbance terms, and long run equilibrium is attained when $f_{t}=s_{t}$. Given that $\omega_{1, t+1}$ and $\omega_{2, t+1}$ are stationary, it follows that the linear combination of $f_{t}$ and $s_{t}$ must also be stationary; hence, $f_{t}$ and $s_{t}$ must be cointegrated with cointegration vector $\left[\begin{array}{ll}1 & -1\end{array}\right]^{\top}$. The essential point is that the error correction representation necessitates the two variables be cointegrated. By using the fact that $z_{t+1}=f_{t+1}-s_{t+1}$,

$$
\begin{aligned}
& \Delta z_{t+1}=\Delta f_{t+1}-\Delta s_{t+1} \\
& \Delta z_{t+1}=\lambda_{2} z_{t}+\omega_{2, t+1}-\lambda_{1} z_{t}-\omega_{1, t+1} \\
& z_{t+1}=\left(1+\lambda_{2}-\lambda_{1}\right) z_{t}+\omega_{2, t+1}-\omega_{1, t+1} \\
& z_{t}=\phi z_{t-1}+\omega_{t} \text { where } \omega_{t}=\omega_{2, t}-\omega_{1, t} \text { and } \phi=1+\lambda_{2}-\lambda_{1}
\end{aligned}
$$

Exploiting the autoregressive structure of the z-process, one can write

$$
\mathrm{z}_{\mathrm{t}+\mathrm{k}}=\phi^{\mathrm{k}} \mathrm{z}_{\mathrm{t}}+\xi_{\mathrm{t}+\mathrm{k}}, \quad \text { with } \quad \xi_{\mathrm{t}+\mathrm{k}}=\sum_{j=0}^{k-1} \phi^{j} \omega_{\mathrm{t}+\mathrm{k}-\mathrm{j}}
$$

By following Berkowitz and Giorgianni (2001), using (9) and recursive solution of (6), the k-period change in the log spot rate can be written as:

$$
S_{\mathrm{t}+\mathrm{k}}-\mathrm{S}_{\mathrm{t}}=\left[\lambda_{1}\left(\frac{1-\phi^{k}}{1-\phi}\right)\right]\left(\mathrm{f}_{\mathrm{t}}-\mathrm{s}_{\mathrm{t}}\right)+\sum_{j=0}^{k-1}\left(\lambda_{1} \varepsilon_{\mathrm{t}+\mathrm{j}}+\omega_{1, \mathrm{t+j}}\right)+\omega_{1, \mathrm{t}+\mathrm{k}} \quad \mathrm{k}=1, \ldots, \mathrm{K}
$$

Now, equation (10) can be compared with long horizon regression (1) such that

$$
S_{\mathrm{t}+\mathrm{k}}-\mathrm{S}_{\mathrm{t}}=\gamma_{\mathrm{k}}\left(\mathrm{f}_{\mathrm{t}}-\mathrm{S}_{\mathrm{t}}\right)+\mathrm{v}_{\mathrm{t}+\mathrm{k}, \mathrm{t}} \text {, where } \gamma_{\mathrm{k}}=\left[\lambda_{1}\left(\frac{1-\phi^{k}}{1-\phi}\right)\right]
$$

As seen in (11), the error correction term or liner combination of $f_{t}$ and $s_{t}$ must be stationary (or equivalently $f_{t}$ and $s_{t}$ are cointegrated). As stated by Berkowitz and Giorgianni (2001), if the fundamentals and exchange rates are not cointegrated, then the tests results are biased toward rejecting the null hypothesis of no predictability.

Now, I conduct a formal assessment of stationarity, using the Augmented Dickey-Fuller (ADF) (1979) and the Kwiatkowski, Phillips, Schmidt and Shin (KPSS) (1992) test to investigate whether or not $z_{t}$ is stationary for the case of Turkey with the cointegration vector $\left[\begin{array}{ll}1 & -1\end{array}\right]^{\top}$ as assumed in (1). KPSS test of 
stationarity is also employed, since unit roots tests have poor power characteristics when the process is stationary but with a root it is close to the nonstationary boundary. Hence, it is sometimes convenient to have stationarity as the null hypothesis.

Table 1. ADF Test Results, $z_{t}=f_{t}-s_{t}=\left(m_{t}-m_{t}^{*}\right)-\left(y_{t}-y_{t}^{*}\right)-s_{t}$

\begin{tabular}{|c|c|c|c|}
\hline \multicolumn{2}{|c|}{} & $\begin{array}{c}\text { Lags } \\
\text { (AIC) }\end{array}$ & $\begin{array}{c}\text { ADF T-Stat } \\
\text { [5\% Critical Value] }\end{array}$ \\
\hline \multirow{3}{*}{ ADF } & Trend and Constant & 5 & $-3.207[-3.494]$ \\
\cline { 2 - 4 } & Constant & 5 & $-0.323[-2.925]$ \\
\cline { 2 - 4 } & None & 5 & $-1.845[-1.950]$ \\
\hline
\end{tabular}

Note: The number of lags specified in the ADF (1979) test are chosen by the Akaike Information Criterion (AIC).

Table 2. KPSS Test Results, $z_{t}=f_{t}-s_{t}=\left(m_{t}-m_{t}^{*}\right)-\left(y_{t}-y_{t}^{*}\right)-s_{t}$

\begin{tabular}{|c|c|c|c|c|}
\hline & $\begin{array}{l}\text { Critical Values at } \\
\% 5 \text { percent level }\end{array}$ & $\begin{array}{l}\text { Test statistic for KPSS test } \\
\text { on } z_{t}\end{array}$ & $\begin{array}{l}\text { Selected Number } \\
\text { of Lags }\end{array}$ \\
\hline \multirow{10}{*}{ KPSS } & \multirow{5}{*}{ Trend } & \multirow{5}{*}{0.146} & 0.446 & 0 \\
\hline & & & 0.285 & 1 \\
\hline & & & 0.218 & 2 \\
\hline & & & 0.185 & 3 \\
\hline & & & 0.173 & 4 \\
\hline & \multirow{5}{*}{ No Trend } & \multirow{5}{*}{0.463} & 5.62 & 0 \\
\hline & & & 2.97 & 1 \\
\hline & & & 2.06 & 2 \\
\hline & & & 1.59 & 3 \\
\hline & & & 1.51 & 4 \\
\hline
\end{tabular}

Note: Serial correlation lag length should be selected to calculate a robust estimate of the variance for the error to conduct KPSS test. Therefore, test results are reported for the different number of lags.

Table 1 and Table 2 display the ADF (1979) and KPSS (1992) test results for the error correction term $z_{t}=f_{t}-s_{t}=\left(m_{t}-m_{t}^{*}\right)-\left(y_{t}-y_{t}^{*}\right)-s_{t}$ in (1). The ADF test results show that $z_{t}$ is nonstationary with the assumed cointegration vector [1 -1$]^{\top}$ for the sample period 2001:Q1-2016:Q2. Also, the KPSS test confirms these results at various selected number of lags. Since these results violate the fact that error correction term must be stationary, the estimation of the long-horizon regression (1) provides biased and unreliable results. For this reason, Mark's (1995) assumptions in (1) will be relaxed in Section 4.2. 


\subsection{Assumptions}

In this section, the VECM is employed to estimate the true cointegration vector $\left[\begin{array}{ll}1 & \beta\end{array}\right]^{\top}$ between fundamentals and exchange rates. When cointegration vector(s) are estimated, two different cases will be considered:

\section{Case A: Zero Interest Rate Differential and Country Specific Income Elasticities}

Since the assumption that the distinct countries have identical income elasticities of money demand is indeed not a realistic assumption, this assumption will be relaxed, and country specific income elasticities of money demand will be imposed. Under the assumption of country specific income elasticities, the composition of $z_{t}$ changes, and it can be rewritten as:

$$
\begin{aligned}
& z_{t}=\beta_{0}\left(m_{t}-m_{t}^{*}\right)-\beta_{1} y_{t}+\beta_{2} y_{t} *-\beta_{3} s_{t} \\
& z_{t}=\beta_{0} m s_{t}-\beta_{1} y_{t}+\beta_{2} y_{t}^{*}-\beta_{3} s_{t}, \text { where } m s_{t}=m_{t}-m_{t}^{*}
\end{aligned}
$$

\section{Case B: Nonzero Interest Rate Differential and Country Specific Income and Interest Rate Elasticities}

Zero interest rate differential assumption in the Case $A$ is reasonable for the countries that are both (numeraire and home) industrialized since interest rate differential between home industrial country and numeraire country (generally the United States) is expected to be about zero. Mark (1995) and Berkowitz and Giorgianni (2001) omit the possible effects of the interest rate differentials in the fundamental value of exchange rates since they investigate the predictability of exchange rates for the industrialized countries. On the other hand, if the home country is an emerging country such as Turkey, and the numeraire country is the United States, then interest rate differential normally turns into a crucial variable ${ }^{2}$.

Similar to the Case A, when estimating the cointegration vector(s), country specific interest rate elasticities are also imposed in addition to the country specific income elasticities. Under the assumption of country specific elasticities, $z_{t}$ can be rewritten as:

$$
\begin{aligned}
& z_{t}=\mu_{0}\left(m_{t}-m_{t}{ }^{*}\right)-\mu_{1} y_{t}+\mu_{2} y_{t}{ }^{*}+\mu_{3} i_{t}-\mu_{4} i_{t}^{*}-\mu_{5} s_{t} \\
& z_{t}=\mu_{0} m s t-\mu_{1} y_{t}+\mu_{2} y_{t}{ }^{*}+\mu_{3} i_{t}-\mu_{4} i_{t}{ }^{*}-\mu_{5} s_{t}, \text { where } m s_{t}=m_{t}-m_{t}^{*}
\end{aligned}
$$

As a result, this study follows a different path from the literature, and the cointegration vectors $\left[\beta_{0}\right.$ $\left.\beta_{1} \quad \beta_{2} \beta_{3}\right]^{\top}$ for the case $A$ and $\left[\begin{array}{llllll}\mu_{0} & \mu_{1} & \mu_{2} & \mu_{3} & \mu_{4} & \mu_{5}\end{array}\right]^{\top}$ for the case $B$, respectively are estimated instead of imposing the cointegration vector a priori, if the cointegration exists. Using the estimated cointegration vector to satisfy the cointegration assumption between fundamentals and exchange rate is the main contribution of this study to the published literature. Also, the main purpose to employ the Case $A$ in addition to the Case $B$ is to be able to compare the possible impacts of two different fundamentals or error correction terms (12) and (13) on exchange rates changes. Normally, it is expected that estimated coefficients under the case B are larger than the same coefficients under the case A for a fundamental-based model due to the empirical validity of interest rate differentials for any emerging country, such as Turkey.

\subsection{Methodology}

\subsubsection{Statistical Approach to Predict Exchange Rate Models}

As stated earlier, several fundamental-based models have been used in the literature to predict exchange rates. The predictive ability of the exchange rate models in literature are measured according to in-sample fit and out-of sample forecast performance.

The in-sample analysis means to estimate the model using all available data. In literature, in-sample fit is evaluated by estimating a model's parameters and $\mathrm{R}^{2}$ 's over the full sample and calculating $\mathrm{t}$-test on 
estimated parameters. When in-sample analysis is carried out in this study, the estimated $z_{\mathrm{t}}^{\prime} \mathrm{s}$ from the equations (12) and (13) are plugged into (1) such that:

$$
s_{t+k}-s_{t}=\alpha_{k}+\gamma_{k} z_{t}+v_{t+k, t} \quad t \quad k=1,2, \ldots ., k
$$

where $z_{t}=\beta_{0} m s_{t}-\beta_{1} y_{t}+\beta_{2} y_{t}^{*}-\beta_{3} s_{t}$ for the case $A$ and,

$z_{t}=\mu_{0} m s t-\mu_{1} y_{t}+\mu_{2} y_{t}{ }^{*}+\mu_{3} i_{t}-\mu_{4} i_{t}{ }^{*}-\mu_{5} s_{t}$ for the case B. Now, $\gamma_{k}$ s can be estimated from the long horizon regression (14) for various $k=1,4,8,12,16$.

The out-of sample analysis has been widely used for evaluating exchange rate models for many years. Since a model that gives the best results in the in-sample analysis does not have to reveal best forecast values, many researchers carry out the out-of sample analysis in addition to the in-sample analysis to choose the best statistical model. To evaluate a model's out-of-sample forecasting ability in the exchange rate literature, the sample is split into two parts: the in-sample portion for estimation (model fitting) and the outof sample portion for evaluating forecasting performance. The model parameters are then re-estimated progressively over time based on the in-sample portions which include all previous data under the (increasing) rolling windows forecast scheme. New forecasts are generated based on these in-sample fits.

On the other hand, the forecasting ability of the ECM model is measured by several loss functions in the literature such that Absolute Forecast Errors (AFE), Mean Absolute Forecast Errors (MAFE), Mean Squared Forecast Errors (MSFE), Root Mean Squared Forecast Errors (RMSFE), etc. Also, the RW is used as the benchmark to make a comparison between the performances of the models. Finally, loss functions are compared for the whole forecasting period to conclude whether the ECM performs better than RW or not ${ }^{3}$.

\subsubsection{Monetary Model in the Johansen VECM Framework}

Following VECM is employed to estimate the true cointegration vector

$\Delta \mathrm{X}_{\mathrm{t}+1}=\mathrm{v}+\Pi \mathrm{X}_{\mathrm{t}}+\sum_{i=0}^{p-1} \Gamma_{\mathrm{i}} \Delta \mathrm{X}_{\mathrm{t}-\mathrm{i}}+\mathrm{u}_{\mathrm{t}+1}$

Where $\mathrm{X}_{\mathrm{t}}=\left[\begin{array}{c}m s_{t} \\ y_{t} \\ y_{t}^{*} \\ s_{t}\end{array}\right]$ is a $4 \times 1$ vector of variables for the Case $\mathrm{A}$, and $\mathrm{X}_{\mathrm{t}}=\left[\begin{array}{c}m s_{t} \\ y_{t} \\ y_{t}^{*} \\ i_{t} \\ i_{t}^{*} \\ s_{t}\end{array}\right]$ is a $6 \times 1$ vector of variables for the

Case B. $v$ is a vector of parameters, and $\varepsilon_{t}$ is vector of disturbances such that $\varepsilon_{t}$ is iid( $\left.0, \Sigma\right)$. Suppose that the vector $X_{t}$ contains integrated of order one, $I(1)$, variables. Everything except the vector $\Pi X_{t}$ in the VECM is integrated of order zero, $I(0)$. This implies that the vector $\Pi X_{t}$ must also be $I(0)$. This is only possible that multiplying $X_{t}$ by $\Pi$ produces the linear combinations of $X_{t}$ that are $I(0)$. When $\Pi$ has reduced rank (or $0<r<4$ for the case $A$ and $0<r<6$ for the Case $B$ ), then it can be expressed as $\Pi=a c^{\top}$, where $c$ is a matrix of the cointegration vectors.

The first step in the Johansen VECM Framework is to pretest each variable to determine its order of integration. ADF (1979) test is conducted to determine the order of integration of each series. Dickey and Fuller (1979) developed a procedure for testing whether a variable $\mathrm{k}_{\mathrm{t}}$ has a unit root or not, and they fit a model of the form

$$
\Delta k_{t}=\Phi+\psi k_{t-1}+\omega t+\sum_{j=1}^{m} \gamma_{j} \Delta k_{t-j}+\rho_{t}
$$

Where $m$ is the number of lags used in the model, and $t$ is time trend. ADF test estimates regression above and tests the null hypothesis of a unit root, $\mathrm{H}_{0}: \psi=0$ versus the alternative of a stationary process for each time series. Additionally, Clemente, Montanes, and Reyes (1998) test is employed to include possible effects of the endogenous breaks on the series when pretesting the variables for their order of integration. Sample period used in the study covers the effects of the global financial crises on Turkish economy and can have the potential of creating structual breaks on the variables. 
O. Tumturk

\section{In Sample Analysis of Exchange Rate Predictability}

\subsection{Estimation Results}

Table 3a. ADF Test Results

\begin{tabular}{|c|c|c|c|c|c|c|}
\hline & \multicolumn{2}{|r|}{ Level } & \multicolumn{3}{|c|}{ First Differences } \\
\hline & & $\begin{array}{l}\text { Lags } \\
\text { (AIC) }\end{array}$ & $\begin{array}{c}\text { ADF T-Stat } \\
\text { [5\% Critical } \\
\text { Value] } \\
\end{array}$ & $\begin{array}{l}\text { Lags } \\
\text { (AIC) }\end{array}$ & $\begin{array}{c}\text { ADF T-Stat } \\
\text { [5\% Critical } \\
\text { Value] }\end{array}$ & Result \\
\hline \multirow{3}{*}{$\mathbf{m}_{\mathrm{t}}$} & Trend and Constant & 1 & $-1.049[-3.490]$ & 0 & $-7.737[-3.490]$ & $I(1)$ \\
\hline & Constant & 1 & $-2.257[-2.922]$ & 0 & $-7.306[-2.922]$ & $\mathrm{I}(1)$ \\
\hline & None & 1 & $-1.871[-1.950]$ & 0 & $-7.066[-1.950]$ & $\mathrm{I}(1)$ \\
\hline \multirow{3}{*}{$\mathbf{y}_{\mathbf{t}}$} & Trend and Constant & 1 & $-1.677[-3.490]$ & 0 & $-7.508[-3.490]$ & $I(1)$ \\
\hline & Constant & 1 & $-1.675[-2.922]$ & 0 & $-7.512[-2.922]$ & $\mathrm{I}(1)$ \\
\hline & None & 1 & $-0.253[-1.950]$ & 0 & $-7.615[-1.950]$ & $\mathrm{I}(1)$ \\
\hline \multirow{3}{*}{$y_{t}{ }^{*}$} & Trend and Constant & 2 & $-2.275[-3.491]$ & 1 & $-3.919[-3.491]$ & $I(1)$ \\
\hline & Constant & 2 & $-1.381[-2.923]$ & 1 & $-3.884[-2.923]$ & $\mathrm{I}(1)$ \\
\hline & None & 2 & $-1.615[-1.950]$ & 1 & $-2.733[-1.950]$ & $\mathrm{I}(1)$ \\
\hline \multirow{3}{*}{$\mathbf{i}_{\mathbf{t}}$} & Trend and Constant & 1 & $-1.498[-3.490]$ & 1 & $-4.771[-3.491]$ & $\mathrm{I}(1)$ \\
\hline & Constant & 1 & $-2.521[-2.922]$ & 1 & $-4.175[-2.923]$ & $\mathrm{I}(1)$ \\
\hline & None & 1 & $-1.701[-1.950]$ & 1 & $-3.425[-1.950]$ & $I(1)$ \\
\hline \multirow{3}{*}{$\mathbf{i}_{\mathbf{t}}{ }^{*}$} & Trend and Constant & 4 & $-2.449[-3.493]$ & 2 & $-4.173[-3.492]$ & $I(1)$ \\
\hline & Constant & 4 & $-1.055[-2.924]$ & 2 & $-4.215[-2.924]$ & $\mathrm{I}(1)$ \\
\hline & None & 4 & $-1.660[-1.950]$ & 2 & $-4.027[-1.950]$ & $\mathrm{I}(1)$ \\
\hline \multirow{3}{*}{$\mathbf{S}_{\mathrm{t}}$} & Trend and Constant & 1 & $-1.749[-3.490]$ & 0 & $-8.049[-3.490]$ & $I(1)$ \\
\hline & Constant & 1 & $-0.343[-2.922]$ & 0 & $-8.094[-2.922]$ & $I(1)$ \\
\hline & None & 1 & $0.977[-1.950]$ & 0 & $-8.002[-1.950]$ & $I(1)$ \\
\hline
\end{tabular}

Table 3b. Clemente, Montanes and Reyes Test Results

\begin{tabular}{|c|c|c|c|c|}
\hline & \multicolumn{2}{|l|}{ Level } & \multicolumn{2}{|c|}{ First Differences } \\
\hline & $\begin{array}{c}\text { Clemente, Montanes, } \\
\text { Reyes T-Stat } \\
\text { [5\% Critical Value] }\end{array}$ & Break Years & $\begin{array}{c}\text { Clemente, Montanes, } \\
\text { Reyes T-Stat } \\
\text { [5\% Critical Value] }\end{array}$ & Break Years \\
\hline$m_{t}$ & $-3.557[-5.490]$ & $\begin{array}{l}2002 Q 4 \\
2013 Q 1\end{array}$ & $-8.768[-5.490]$ & $\begin{array}{l}2008 Q 2 \\
2009 Q 2\end{array}$ \\
\hline$y_{t}$ & $-5.490[-5.813]$ & $\begin{array}{l}\text { 2002Q4 } \\
2015 Q 3\end{array}$ & $-8.938[-5.490]$ & $\begin{array}{l}2003 Q 4 \\
2008 Q 3\end{array}$ \\
\hline$y_{t}{ }^{*}$ & $-2.996[-5.490]$ & $\begin{array}{l}2002 Q 4 \\
2011 Q 1\end{array}$ & $-7.024[-5.490]$ & $\begin{array}{l}2008 Q 2 \\
2009 Q 2\end{array}$ \\
\hline $\mathbf{i}_{\mathbf{t}}$ & $-4.531[-5.490]$ & $\begin{array}{l}2003 Q 1 \\
2008 Q 3\end{array}$ & $-5.738[-5.490]$ & $\begin{array}{l}2005 Q 3 \\
2008 Q 4\end{array}$ \\
\hline $\mathbf{i}_{\mathbf{t}} *$ & $-4.907[-5.490]$ & $\begin{array}{l}2008 Q 2 \\
2011 Q 1\end{array}$ & $-8.380[-5.490]$ & $\begin{array}{l}2006 Q 1 \\
2013 Q 2\end{array}$ \\
\hline $\mathbf{S}_{\mathrm{t}}$ & $-3.901[-5.490]$ & $\begin{array}{l}2008 Q 2 \\
2013 Q 1\end{array}$ & $-8.790[-5.490]$ & $\begin{array}{l}\text { 2008Q3 } \\
2014 Q 4\end{array}$ \\
\hline
\end{tabular}


As is standard in time series analysis, the statistical properties of the variables are examined using ADF (1979) unit root tests ${ }^{4}$. ADF unit root test results depend on the which version of test is used: trend and constant, constant, and none. Table $3 a$ reveals that all variables in $X_{t}$ are I(1). Table $3 b$, on the other hand, confirms the ADF test results when two endogenous breaks are considered.

Since all variables are I(1), Johansen (1991) methodology can be followed in order to test the cointegration relation for the variables in each case. The number of lags included in the Vector Autoregression (VAR) must be specified to test for cointegration. Hence, five and one lags are included in the VAR for the Case A and Case B, respectively based on the AIC. Also, it is allowed the level data to have trends. Johansen's cointegration procedure starts with the test for zero cointegration ( $\operatorname{rank}(r)=0$ ) equations and then accepts the first null hypothesis that is not rejected. The bodies of the Tables 4 and 5 present test statistics and their critical values of the null hypotheses of no cointegration and one or more cointegration equations for each case.

Table 4. Determination of Rank, Case A

\begin{tabular}{|c|c|c|c|}
\hline $\begin{array}{c}\text { Null } \\
\text { Hypothesis }\end{array}$ & $\begin{array}{c}\text { Alternative } \\
\text { Hypothesis }\end{array}$ & $\begin{array}{c}\text { Trace } \\
\text { Statistics }\end{array}$ & $\begin{array}{c}\mathbf{5 \%} \text { critical } \\
\text { value }\end{array}$ \\
\hline$r=0$ & $r=1$ & 80.70 & 62.99 \\
\hline$r=1$ & $r=2$ & 48.20 & 42.44 \\
\hline$r=2$ & $r=3$ & $\mathbf{2 3 . 1 2}$ & $\mathbf{2 5 . 3 2}$ \\
\hline$r=3$ & $r=4$ & 11.17 & 12.25 \\
\hline
\end{tabular}

Table 5. Determination of Rank, Case B

\begin{tabular}{|c|c|c|c|}
\hline $\begin{array}{c}\text { Null } \\
\text { Hypothesis }\end{array}$ & $\begin{array}{c}\text { Alternative } \\
\text { Hypothesis }\end{array}$ & $\begin{array}{c}\text { Trace } \\
\text { Statistics }\end{array}$ & $\begin{array}{c}\mathbf{5 \%} \text { critical } \\
\text { value }\end{array}$ \\
\hline$r=0$ & $r=1$ & 162.29 & 114.90 \\
\hline$r=1$ & $r=2$ & 98.70 & 87.31 \\
\hline$r=2$ & $r=3$ & 49.77 & 62.99 \\
\hline$r=3$ & $r=4$ & 26.96 & 42.44 \\
\hline$r=4$ & $r=5$ & 10.86 & 25.32 \\
\hline$r=5$ & $r=6$ & 2.73 & 12.25 \\
\hline
\end{tabular}

Table 6. Estimation Results of Cointegration Vectors

\begin{tabular}{|c|c|c|c|}
\hline Cointegration Vector & Case A & Cointegration Vector & Case B \\
\hline$\beta_{0}$ & 1 & $\mu_{0}$ & 1 \\
\hline$\beta_{1}$ & $3.601^{*}$ & $\mu_{1}$ & $1.308^{*}$ \\
\hline$\beta_{2}$ & 1 & $\mu_{2}$ & 1 \\
\hline$\beta_{3}$ & $-2.607^{*}$ & $\mu_{3}$ & $0.008^{*}$ \\
\hline & & $\mu_{4}$ & $0.027^{*}$ \\
\hline & & $\mu_{5}$ & $-0.262^{*}$ \\
\hline
\end{tabular}

Note: Johansen normalization restriction on the coefficients of $\mathrm{mst}_{\mathrm{t}}$ and $\mathrm{yt}_{\mathrm{t}}^{*}$ is one for both cases. ${ }^{*}$ shows that estimated cointegration coefficients are statistically significant at the 5 percent level. When presenting the estimated cointegration vectors obtained from VECM in Table 6, only one of them is reported for each case based on the statistical significance and theoretical sign of the estimated cointegration coefficients. 
Tables 4 and 5 suggest that there are two cointegration vectors $(r=2)$ for both cases while Table 6 presents the estimation results of corresponding cointegration vectors. According to the Johansen (1995) procedure, if there are $r=2$ cointegrating equations, then at least $r^{2}=4$ restrictions are required to identify the free parameters in the cointegration vectors. Thus, four restrictions are imposed for two cointegration vectors for each case separately. Johansen normalization restrictions on the coefficients of $\mathrm{ms}_{\mathrm{t}}$ and $\mathrm{y}_{\mathrm{t}}{ }^{*}$ are chosen "one" for both cases. ${ }^{5}$. It is important to highlight that the main purpose of the estimating cointegration vectors is not to estimate the magnitude of money demand elasticities for Turkey and the United States, but to estimate the country specific elasticities for distinct countries consistent with the assumptions in 4.2 .

Now, $z_{\mathrm{t}}$ can be formed based on the VECM estimation results. After plugging the estimated $z_{\mathrm{t}}$ into the equation (14), one can estimate the regression (14) for different $k=1,4,8,12,16^{6}$.

Table 7. Regression Results

\begin{tabular}{|c|c|c|c|c|c|c|}
\hline & \multicolumn{3}{|c|}{ Case $\mathbf{A}$} & \multicolumn{3}{c|}{ Case B } \\
\hline $\mathbf{k}$ & $\mathbf{V}_{\mathbf{k}}$ & $\mathbf{R}^{\mathbf{2}}$ & $\mathbf{M S L}$ & $\mathbf{V k}_{\mathbf{k}}$ & $\mathbf{R}^{\mathbf{2}}$ & $\mathbf{M S L}$ \\
\hline $\mathbf{1}$ & 0.154 & 0.022 & 0.122 & 0.076 & 0.051 & 0.384 \\
\hline $\mathbf{4}$ & 0.046 & 0.031 & 0.725 & 0.0201 & 0.062 & 0.904 \\
\hline $\mathbf{8}$ & 0.075 & 0.101 & 0.607 & 0.193 & 0.063 & 0.441 \\
\hline $\mathbf{1 2}$ & 0.341 & 0.286 & 0.094 & 0.427 & 0.245 & 0.103 \\
\hline $\mathbf{1 6}$ & 0.450 & 0.281 & 0.032 & 0.527 & 0.274 & 0.055 \\
\hline
\end{tabular}

Note: The methodology to compute heteroskedasticity and autocorrelation consistent (HAC) standard errors was developed by Newey and West (1987); thus, they are referred to as Newey-West standard errors. The NeweyWest standard errors are used to adjust the covariance matrix of the parameters and produce consistent estimates when there is autocorrelation in addition to possible heteroskedasticity. HAC standard errors are calculated conditionally on a choice of maximum lag. I follow Stock and Watson (2012) and determine the number of lags by $L=0.75 T^{1 / 3}$, where $T$ is the sample length. Since $T=62$, lag length used in this study is 3 .

Table 7 contains the estimated slope coefficients $\left(\nu_{k}\right), R^{2 \prime} s$, and marginal significance levels (MSL). The slope coefficients and $\mathrm{R}^{2}$ 's are getting higher in magnitude when $\mathrm{k}$ is extended to 12 and 16 quarters. On the other hand, slope coefficients are only significant at $k=12$ and 16 at ten percent level. These results suggest that the fundamentals are useful to explain the changes in the logarithm of exchange rates in the long run. Also, the statistically significant coefficients in the case A are smaller than the statistically significant coefficients in the case $B$, as expected. Last result presents the evidence that the interest rate differentials are crucial to explain the predictive ability of the ECM model in an emerging country such as Turkey.

\section{Out-of Sample Analysis of Exchange Rate Predictability}

In this section, the same long horizon regression is employed such that;

$$
S_{t+k}-S_{t}=\alpha_{k}+\gamma_{k}\left(f_{t}-s_{t}\right)+v_{t+k, t} \quad t \quad k=1,2, \ldots . ., K
$$

where $f_{t}=m s_{t}-1.308 y_{t}+y_{t}{ }^{*}+0.008 i_{t}-0.027 i_{t}{ }^{*}+0.262 e_{t}$. Since interest rate differential is crucial factor for the case of Turkey, I employed $z_{t}$ obtained by (13).

\subsection{The Forecast Procedure}

As discussed in Section 4.3.1, the (increasing) rolling windows forecast scheme includes reestimation of model parameters progressively over time based on the in-sample portions which include all previous data. However, economic agents have the tendency to use recent observations rather than the old observations when they are forecasting. When out-of sample analysis is carried out, rolling regressions with fixed windows (or in-sample portions) will be employed instead of increasing windows to measure $\alpha_{k}$ and $\gamma_{k}$ in (15). Therefore, the forecast values will be derived from the most recent observations. Additionally, since 
the ECM reveals the best in-sample analysis results in the long run, the forecast errors are calculated by $k=12$ and 16 quarters.

To evaluate the ECM model's out-of sample forecasting ability, the sample is split into two parts: the in-sample portion and out-of sample portion. Initial in-sample portion is 2001:Q1-2007:Q4. The ECM model is initially estimated for the exchange rate using data up to but not including the first forecasting period, 2008:Q1, and the forecast value for 2008:Q1 is generated. Then, the data for 2008:Q1 are added into the insample portion, and the data for 2001:Q1 are left out from it. The ECM is re-estimated for the new sample 2001:Q2-2008:Q1 using rolling regressions with fixed in-sample portions, and the forecast value for 2008:Q2 is generated, etc. It is important to note that the each in-sample portion has the same sample size (28 quarters) for each regression. This procedure ends when the in-sample portion includes 2005:Q3-2012:Q2 period when $k=16$. Same procedure is followed for $k=12$, and forecast values are produced ${ }^{7}$.

The forecasting power of the model (15) is evaluated by Absolute Forecast Errors (AFE) and Mean Absolute Forecast Errors (MAFE). Since the ECM model produces the best results at $k=12$ and 16 quarters, AFE is calculated by the horizontal sum of forecast errors at $k=12$ and 16 quarters. Also, the ECM is considered successful or unsuccessful based on their ability to produce better forecasts than the benchmark RW model consistent with the exchange rate literature. According to the RW, the best predictor of exchange rates tomorrow is the exchange rate today such that;

$$
E_{t} S_{t+k}-S_{t}=0
$$

Finally, to investigate that the model forecasts are significantly better than the RW, t-test is conducted to evaluate whether MAFE for ECM (MAFE $\mathrm{ECM}_{\mathrm{E}}$ ) - MAFE for the RW (MAFE $\mathrm{RW}_{\mathrm{RW}}$ ) is equal to zero against the alternative that the difference is negative.

Tsay (2008) suggests that a reasonable choice regarding the size of the in-sample portion is $T / 2$ (32 observations) for large T or $2 \mathrm{~T} / 3$ (41 observations) otherwise. However, in-sample portion is narrowed down to 28 observations $^{8}$ (2001:Q1-2007:Q4) to investigate whether or not the 2008 economic recession in Turkey has any possible impact onto predictive ability of the ECM in (15).

\subsection{The Forecast Results}

The body of the Figure 1 shows the AFE's for the both RW and ECM over the out-of sample period of 2008:Q1 and 2013:Q2. The blue line shows the AFE's for the ECM, and orange line represents the AFE's for the RW model. As shown in Figure 1, the ECM beats the RW during the whole out-of sample period. MAFEECM and $\mathrm{MAFE}_{\mathrm{RW}}$ are also calculated and added to Table 8 to compare the forecast errors in Figure 1 numerically. Based on the t-test results, the differences between $M_{A F E} E_{E M}$ and $M_{A F E}$ is found to be statistically significant at five percent level. The results in Table 7 reveal that that monetary fundamentals are crucial to forecast the exchange rate changes in Turkey in the long run.

Before finishing this section, one more point is worth mentioning. Based on Figure 1, concluding that exchange rates changes in Turkey can be predicted by monetary fundamentals is correct but not an enough statement to end the out-of sample analysis. As shown in the shaded area in Figure 2, Turkey has recession period $^{9}$ over the period of 2008:Q2 and 2009:Q1. Figure 1 interestingly reveals that even though the ECM model beats the RW during the whole forecast period, there is a subperiod (2008:Q4 and 2009:Q1) associated with the recession time such that the RW model also outperforms the ECM model. This interesting point requires some explanation.

Economies might have recession periods, and recession periods are characterized by short termism and elevated information uncertainty in the markets. Bloom (2014) states that uncertainty appears to increase during recessions since lower economic growth causes greater micro and macro uncertainty. For example, the volatility of stock markets, bond markets, exchange rates, and GDP growth all rise sharply in recessions, and the macro uncertainty and short termism increases. Hence, it is reasonable to expect that RW model that gives more weight to current information performs well in recessions. On the other hand, exchange rate models are expected to explain the exchange rate behavior when the future growth prospects 
of the economy are known with more certainty. Therefore, exchange rate models are expected to work better apart from the recession periods.

Figure 1. Absolute Forecast Errors

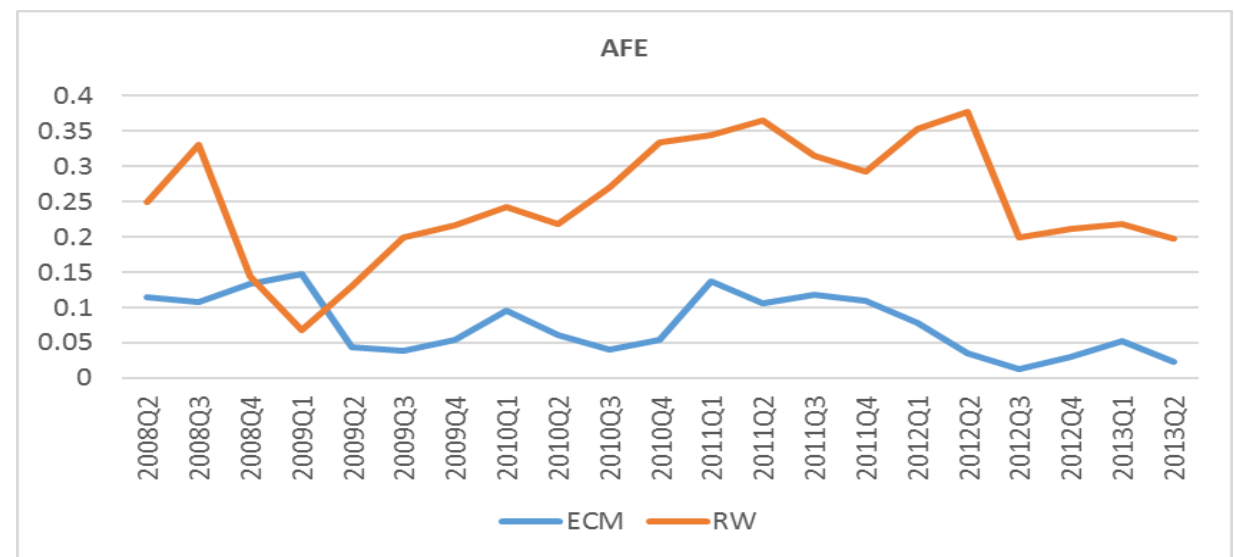

Note: AFE for the ECM and RW models are obtained by the sum of the forecast errors at $k=12$ and 16 quarters horizontally.

Table 8. $\mathrm{MAFE}_{\mathrm{ECM}} / \mathrm{MAFE}_{\mathrm{RW}}$ Ratio and t-test Results

\begin{tabular}{|c|c|}
\hline Turkey & 2008:Q1-2013:Q2 \\
\hline MAFE $_{\mathrm{ECM}}$ & 0.085 \\
\hline MAFE $_{\mathrm{RW}}$ & 0.253 \\
\hline $\mathrm{MAFE}_{\mathrm{ECM}} / \mathrm{MAFE}_{\mathrm{RW}}$ & $0.337^{*}$ \\
\hline
\end{tabular}

Note: The coefficients show the ratio MAFE $E_{E C M} / M_{\text {MFE }}$ for the 2008:Q1-2013:Q2 forecast period. * denotes the null hypothesis that MAFE $E_{E C M}-M A F E_{R W}$ is equal to zero (against the alternative that the difference is negative) is rejected at 5 percent level. Hence, ECM significantly beats the RW model, suggesting that MAFE $E_{E C M} / M_{A F E}$ ratio is significantly less than 1.

Figure 2. Real GDP Growth (Quarterly)

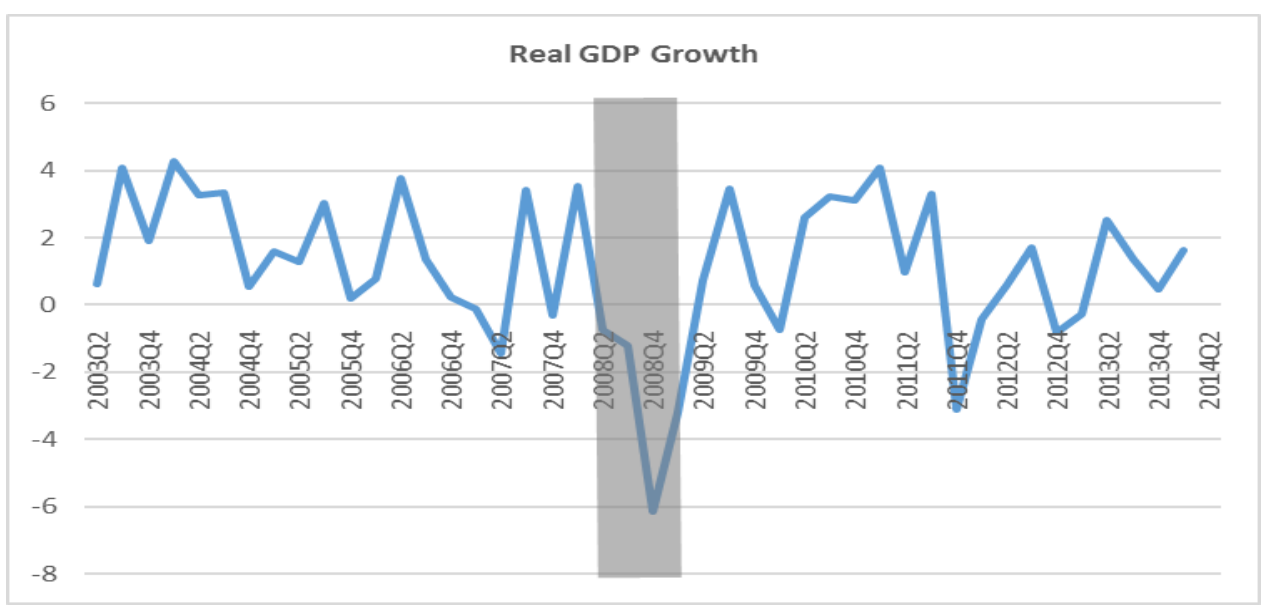

Note: Adapted from https://stats.oecd.org/index.aspx?queryid=60702. Copyright 2016 by OECD 
Based on the general explanation above, let me turn back to Figure 1. When the economic recession begins in 2008:Q2, the economic agents in Turkey start to give more weights to the current information. Therefore, the RW forecast errors dramatically decline and fall below the forecast errors obtained from the ECM between 2008:Q4 and 2009:Q1. But then, the recession ends in 2009:Q2, and economic agents in Turkey again adjust their expectations on exchange rates by observing monetary fundamentals over the period of 2009:Q2 and 2013:Q2. As a result, while the ECM outperforms the RW model for the whole forecast period, the RW model performs better than the ECM during the 2008 recession. This result implies that taking the average of forecast errors for the whole forecast period without subsample analysis will lead researchers to lose quite valuable information such that recession period causes to reduce predictive ability of the fundamentals in Turkey.

\section{Conclusion}

This study investigates the predictability of exchange rates in Turkey by using the long horizon regression or ECM derived from the VECM. The VECM is employed to estimate the true cointegration vector between fundamentals and exchange rate to overcome the stationarity problem of the error correction term $\mathrm{z}_{\mathrm{t}}$ and avoid biased results. When estimating the cointegration vector, two different assumptions are imposed: zero and nonzero interest rate differential and country specific money demand elasticities.

The in-sample analysis results suggest that the fundamentals in Turkey are useful to explain the long horizon changes in the logarithm of the exchange rates under the assumption of country specific elasticities. Lengthening the k-period-ahead change to $k=12$ and $k=16$ results in rising values of $\gamma_{k}$ and $R_{k}{ }^{2} s$, and makes $\gamma_{\mathrm{k}}$ values significant. Also, the predictive ability of the ECM model significantly improves when the analysis contains interest rate differentials. On the other hand, out-of sample analysis results based on the most recent observations suggest that the ECM outperforms the RW model during the forecast period 2008:Q12013:Q2 in Turkey. These results reveal that there exists an economically significant predictable component in long-run changes in the exchange rates in Turkey, as suggested by Mark (1995).

Even though the ECM significantly dominates the RW over the whole forecast period, the RW model beats the ECM model during the 2008 recession. To put it another way, whether the ECM or the RW explains the nature of exchange rate changes might be considered that time varying. During recessions, the forecast values obtained from RW model explains the exchange rates changes better due to the elevated information uncertainty and short termism. The last result implies that the predictions based upon the fundamentals regarding the long run changes in exchange rates during the "non-crisis periods or usual periods" are expected to be more reliable than "crisis periods or unusual periods". Hence, when evaluating the predictive power of fundamentals on exchange rates in Turkey, one should consider the current phase of the business cycles as reliability of the predictions are closely related to these cycles.

This study, being of an explanatory and interpretive nature, raises some opportunities for future research. First, the results of the study might be verified by using future fundamentals in addition to the current fundamentals. Engel and West (2005) claim that exchange rate models can be written in a present value asset-pricing format, and exchange rates are determined not only by current fundamentals but also by expectations of what the fundamentals will be in the future. Second, the time varying nature of the out-of sample results can be verified by analyzing other emerging countries to be able to conclude that the results of the study are also valid in all emerging countries.

\section{End Notes}

1. This article is adapted from the unpublished doctorate thesis in Economics titled as "The Predictability of Exchange Rates" defended by Oguz Tumturk in 2016 at the University of Kansas.

2. This claim can be explained by UIP which briefly states that interest rate differentials affect the exchange rates. That is, under the assumption floating exchange rates, a nation that has relatively high real interest rates finds its currency appreciating. If funds flow freely across countries, the exchange rate between two countries is expected to change such that the TL return on TL deposits is equal to the TL return on foreign deposit. 
3. The out-of sample forecast procedure followed by literature in Section 4.3 .1 will be slightly changed later, and details will be discussed in Section 6.1.

4. In addition to the ADF (1979) unit root test, Phillips-Perron (1988), KPSS (1992), and Zivot-Andrews (1992) tests are also employed. Phillips-Perron test uses Newey-West standart errors to account for serial correlation. Zivot-Andrews (1992) test is conducted based on the principle of endogenous determination of single structural break. The test results are the same as those for the ADF and Clemente, Montanes, and Reyes (1998) tests and available upon request.

5. The corresponding cointegration vector coefficient on $y_{t}^{*}$ is the income elasticity of money demand in the United States, and many leading studies including Lucas (2000), Ireland (2009) and Serletis and Yavari (2004) impose unit income elasticity for the United States.

6. Using the estimated cointegration vectors to form $z_{t}$ and plugged $z_{t}$ into (14) may cause generated regressors problem. Basically, an estimate of $z_{t}$ is employed in the regression (14). The implication of generated regressors is biased standard errors, which impede proper inference making. However, the generated regressor problem here will not prevent one to obtain proper inference making. Pagan (1984) states that if one only tests the hypothesis $\gamma_{k}=0$, the regression of $s_{t+k}-s_{t}$ against $z_{t}$ yields all the information necessary and the estimator is perfectly efficient. The OLS estimator of the variance of $\gamma_{k}$ is consistent, and the "asymptotic t-statistics" are valid.

7. The out of-sample periods with respect to $k=16$ and $k=12$ are 2008:Q1-20012:Q2 and 2008:Q1-2013:Q2, respectively.

8. Various sizes of in-sample portions are also used such as 20,32 (T/2) and 41 (2T/3) quarters. Since different in-sample portions present similar results, the results are only reported for 28 quarters as seen in Figure 1. The estimation results are available from the author upon request.

9. In literature, the main indicator of a recession is two or more consecutive quarters of negative growth. O'Sullivan and Sheffrin (2007) state that "if real GDP falls for two consecutive quarters, then the economy is said to be in recession" (p. 311).

\section{References}

Berkowitz, J., \& Giorgiannni, L. (2001) Long-horizon exchange rate predictability?. Review of Economics and Statistics, 83, 81- 91 .

Bloom, N. (2014). Fluctuations in Uncertainty. The Journal of Economic Perspectives, 28(2), 153-176.

Cerra, V., \& Saxena, C.S. (2010). The monetary model strikes back: evidence from the world. Journal of International Economics, 81, 184-196

Chinn, M., \& Meese, R.A. (1995). Banking on currency forecasts: how predictable is change in money?. Journal of International Economics, 38(1), 161-178.

Clemente, J., Montanes, A., \& Reyes, M. (1998). Testing for a unit root in variables with a double change in the mean. Economics Letters, 59(2), 175-182.

Dickey, D. A., \& Fuller, W. A. (1979). Distribution of the estimators for autoregressive time series with a unit root. Journal of the American Statistical Association, 74(366), 427-431.

Diebold, F., Gardeazabal, J., \& Yilmaz, K. (1994). On cointegration and exchange rate dynamics. Journal of Finance, 49 (2), 727-735.

Dabrowski, M.A., Papiez, M., \& Smiech, S. (2014). Exchange rates and monetary fundamentals in CEE countries: Evidence from a panel approach. Journal of Macroeconomics, 2014, 41, 148-159.

Engel, C.M. (1994). Can the Markov Switching model forecast exchange rates?. Journal of International Economics, 36, $151-165$.

Engel, C., \& West, K.D. (2005). Exchange rates and fundamentals. The Journal of Political Economy, 113(3), 485-517.

Engel, C., Mark N.C., \& West, K.D. (2007). Exchange rate models are not as bad as you think. NBER Macroeconomics Annual, 22, 381- 441.

Frommel, M., Macdonald, R., \& Menkhoff, L. (2005). Markov Switching regimes in a monetary exchange rate model. Economic Modelling, 22(3), 485-502.

Galimberti, J.K., \& Moura, M.L. (2013). Taylor Rules and exchange rate predictability in emerging economies. Journal of International Money and Finance, 32, 1008-1031.

Groen, J. (1999). Long horizon predictability of exchange rates: is it for real. Empirical Economics, 24(3), 451-469. 
Groen, J.J. (2005). Exchange rate predictability and monetary fundamentals in a small multi-country panel. Journal of Money, Credit and Banking, 37(3), 495-516.

Ireland, P. (2009). On the welfare cost of inflation and the recent behavior of money demand. American Economic Review, 99(3), 1040-1052.

Johansen, S. (1991). Estimation and hypothesis testing of cointegration vectors in Gaussian vector autoregressive models. Econometrica, 59(6), 1551-1580.

Johansen, S. (1995). Likelihood-based inference in cointegrated vector autoregressive models. Oxford: Oxford University Press.

Kilian, L. (1999). Exchange rates and monetary fundamentals: what do we learn from long-horizon regressions. Journal of Applied Econometrics, 14(5), 491-510.

Korap, L. (2008). Exchange rate determination of TL/US\$: a co-integration approach. Ekonometri ve Istatistik, 7, 24-50,

Lucas, R. E. (2000). Inflation and welfare. Econometrica, 68(2), p. 247-274.

Kwiatkowski, D., Phillips, P. C. B., Schmidt, P., \& Shin, Y. (1992). Testing the null hypothesis of stationarity against the alternative of a unit root. Journal of Econometrics, 54,159-178.

Macdonald, R., \& Taylor, M.P. (1993). The monetary approach to the exchange rate: rational expectations, long-run equilibrium, and forecasting. IMF Staff Papers, 40(1), 89-107.

Mahavan, A., \& Wagner, A.J. (1999). Nonlinear dynamics in foreign exchange rates. Global Finance Journal, 10(1), 1-23.

Mark, N. (1995). Exchange rates and fundamentals: evidence on long-horizon predictability. American Economic Review, 85 (1), 201- 218.

Mark, N.C., \& Sul, D. (2001). Nominal exchange rates and monetary fundamentals: evidence from a small post-Bretton Woods panel. Journal of International Economics, 53 (1), 29-52.

Marsh, I. W. (2000). High-frequency markov switching models in the foreign exchange market. Journal of Forecasting, $19(2), 123-134$.

Meese, R.A., \& Rogoff, K. (1983). Empirical exchange rate models of the seventies: Do they fit out of sample. Journal of International Economics, 14, 3-24.

Newey, W. K., \& West, K.D. (1987). A simple, positive semi-definite, heteroskedasticity and autocorrelation consistent covariance matrix. Econometrica, 55(3), 703-708.

O'sullivan, A., \& Sheffrin, S. M. (2007). Economics: principles in actions. Boston: Pearson.

Pagan, A. (1984). Econometric issues in the analysis of regressions with generated regressors. International Economic Review, 25(1), 221-247.

Phillips, P. C. B., \& Perron P. (1988). Testing for a unit root in time series regression. Biometrika 75(2), 335-346.

Rapach, D., \& Wohar, M. (2002). Testing the monetary model of exchange rate determination: New evidence from a century of data. Journal of International Economics, 58(2), 359- 385.

Schwarz, G. E. (1978). Estimating the dimension of a model. Annals of Statistics, 6(2), 461-464.

Serletis, A., \& Yavari, K. (2004). The welfare costs of inflation in Canada and the United States. Economics Letters, 84, 199-204.

Stock J. H., \& Watson M. W. (2012). Introduction to econometrics. Boston: Pearson.

Taylor, M. P., \& Peel, D.A. (2000). Nonlinear adjustment, long-run equilibrium and exchange rate fundamentals. Journal of International Money and Finance, 19(1), 33-53.

Tsay, R. (2008). Univariate volatility models (out-of-sample forecasts). Retrieved August 18, 2016, from http://faculty.chicagobooth.edu/ruey.tsay/teaching/bs41202/sp2008/lec4a-08.pdf

Uz, I., \& Ketenci, N. (2008). Panel analysis of the monetary approach to exchange rates: Evidence from ten new EU members and Turkey. Emerging Markets Review. 9 (1), 57-69.

Zivot, E., \& Andrews, D.W.K. (1992). Further evidence on the great crash, the oil-priceshock, and the unit-root hyphothesis. Journal of Business \& Economic Statistics, 10 (3), 251-270. 